\title{
Experiments and Numerical Modeling of a Rockfall Protective Wire Rope Fence
}

\author{
Phuc Tran Van and Koji Maegawa \\ Graduate School of Natural Science and Technology, Kanazawa University, Japan
}

\begin{abstract}
To protect existing structures in mountainous areas against rockfall, various protection methods have been developed. A new type of rockfall protection fence is constructed of posts, wire ropes, and wire netting. To verify the performance of this rock fence, both experiments and numerical analysis based on finite element code were conducted. Collision tests were performed, in which a reinforced-concrete block rolled down a natural slope and struck the rock fence at the end of the slope. The performance of energy absorbers, which are effective in preventing wire ropes from breaking, was investigated. To measure the acceleration of a reinforced-concrete block rolling down a steep slope, a new system of measuring instruments was developed.
\end{abstract}

Keywords: rockfall, rock fence, wire rope, energy absorber.

\section{INTRODUCTION}

Rockfall presents an extreme hazard to transportation routes and underlying infrastructure in steep mountainous terrain. Thus, in many mountainous areas, highways, railways and urbanized regions have been protected against rockfall with deformable rock fences. Many of these fences have been constructed in recent years throughout the world. However, the design scheme of these systems has been primary based on empirical methods, engineering judgment, and experiment. Slope rockfall tests are performed for full-scale physical models to determine the maximum impact energy that can be sustained by a fence. The tests are generally carried out using large natural or artificial regular-shaped blocks, which collide with predetermined target points on the fence [1]. It should be emphasized that, for the very particular nature of the test conditions, it is verified that the fence is able to withstand a certain impact energy, but without deeper understanding of the performance of each individual component and the whole system as a whole.

In this study, a new type of rock fence made of posts, wire ropes, and special devices is shown to have a remarkable capacity to catch rocks and thereby prevent damage to vehicles and houses, as well as fatalities. In Japan, all rock fences are designed according to a desired energy-absorption capacity [2]. To absorb a large amount of energy, the wire rope of the high-energy rock fence is semi-fastened to a post using an energy-absorbing device [3]. When pulled, the wire rope does not slip from the device until the magnitude of the friction force exceeds a critical value, which can be controlled. As the wire rope slips, the device is able to maintain a fluctuating kinetic friction force until a stopper located at the end of the rope comes into contact with the energy absorber. The wire rope thus does not break and part of the impact energy is absorbed by the energy absorber.

Two types of energy absorber will be introduced and examined with respect to their configuration and corresponding energy-dissipation behavior. These devices generally account for a significant proportion of the total cost of the fences. Therefore, to reduce the number of energy absorbers and achieve lower cost while maintaining performance, energy absorbers are installed only at the end posts in the new type of fence. The new type of rock fence is examined in full-scale experiments carried out using a falling reinforced-concrete (RC) block that rolls down a natural slope without a navigation system for the block. In preparation for these tests, laboratory pre-tests on such components as energy absorbers, posts, and wire ropes were conducted to confirm their load-carrying capacities and structural behaviors. Furthermore, an experimental control system is introduced to investigate the impact force during collision. Moreover, numerical simulation was performed employing finite element code, LS-DYNA, to clarify the impact behavior by comparing numerical results with those obtained in actual-scale tests.

\section{CONFIGURATION OF THE ROCK FENCE}

\subsection{Details of the Rock Fence}

Fig. 1 shows the configuration and dimensions of the rock fence. Four posts made of concrete-filled steel tubes were erected on a concrete foundation. Wire ropes, steel tubes (as horizontal braces), steel plates (as vertical braces) to maintain the spacing between wire ropes, wire netting, and energy absorbers were then assembled. The fence consisted of three spans with lengths of 5,8 , and $5 \mathrm{~m}$. The main wire ropes were semi-fastened to both end posts via energy absorbers. There was no energy absorber connected to the intermediate posts. Instead, steel rings welded to the intermediate posts supported the wire rope. The extension length of each wire rope from the energy absorber was 1400 $\mathrm{mm}$, and a stopper was attached at the end of the wire rope to prevent the wire rope from sliding out of the energy absorber. Two types of energy absorber were used, as shown in Fig. 2.

The energy absorber consisted of a U-shaped bolt and two types of steel block that could not be separated from the U-bolt. Each steel block consisted of two steel plates with thicknesses of 25 to $38 \mathrm{~mm}$, and the concave indentations in both plates held in place a wire rope when the steel plates 
were compressed together by two M20 bolts at $200 \mathrm{Nm} /$ bolt. The magnitude of the torque could be altered to control the critical friction force. As shown in Figs. 2a and 2b, the two types of energy absorber differ in the interval between the two steel blocks. In the Type-B energy absorber, the smaller steel block can initially slide along the U-bolt. Consequently, the axial force on the wire rope depends only on the friction between the larger steel block and the wire rope, until the smaller steel block contacts the larger steel block. In contrast, in the Type-A energy absorber, there is no interval between the two steel blocks. Therefore, the axial force acting on the wire rope depends on the friction between the two steel blocks and the wire rope immediately after impact. The structure of the Type-B energy absorber is effective in gradually increasing the tension on the wire rope and may prevent the wire ropes from breaking.

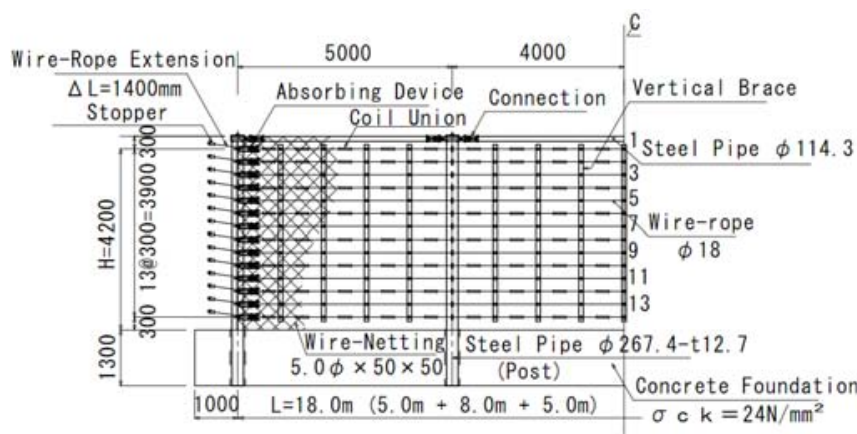

Fig. 1 Configuration and dimensions of the rock fence

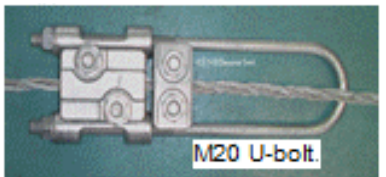

Fig. 2a Absorber (Type A)

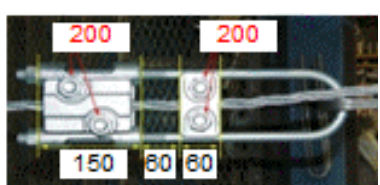

Fig. 2b Absorber (Type B)

\subsection{Experimental Control System}

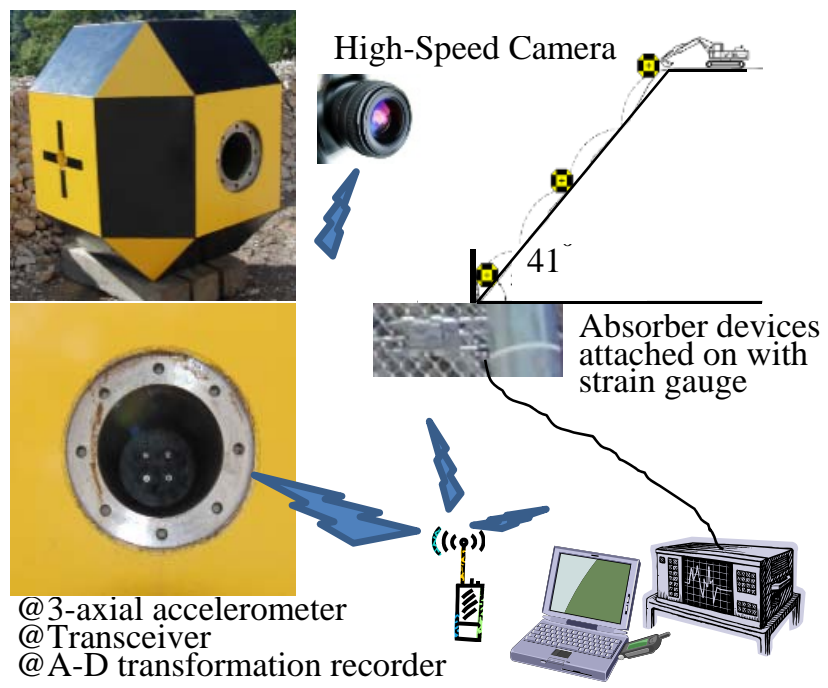

Fig. 3 Experimental control system

A number of devices are needed to control the experimental process and collect data. The control system synchronizes these devices. Fig. 3 shows the experimental control system.
An electric cable connection was not suitable for collecting the acceleration data of the RC block because the RC block fell and rolled down a steep slope. Thus, a three-axis accelerometer, analog-to-digital transformation recorder, and transceiver were placed inside the RC block. The transceiver sent a trigger signal to the analog-to-digital transformation recorder immediately after receiving a signal from the master transceiver, which was used to start collecting data. Another analog-to-digital transformation recorder collected the data from strain gauges attached to the energy absorbers without delay as the master transceiver emitted the signal. High-speed cameras (300 frames/second) recording the impact were placed at the most appropriate positions to ensure that the interaction between the RC block and rock fence was recorded clearly. A high-speed camera (600 frames/second) started recording shortly before the collision in response to the signal emitted by the master transceiver, and the recording was used for the detailed monitoring of the instant that the $\mathrm{RC}$ block impacted on the fence.

\section{OUTLINE OF THE EXPERIMENTS}

\subsection{Test of the Rock Fence}

Two tests were carried out. The sole difference between the tests was that Type-A and Type-B energy absorbers were applied in Tests No. 1 and No. 2, respectively. The mass of the weight and its falling height were identical in the two tests. After Test No. 1, all components other than the posts were replaced with new ones.

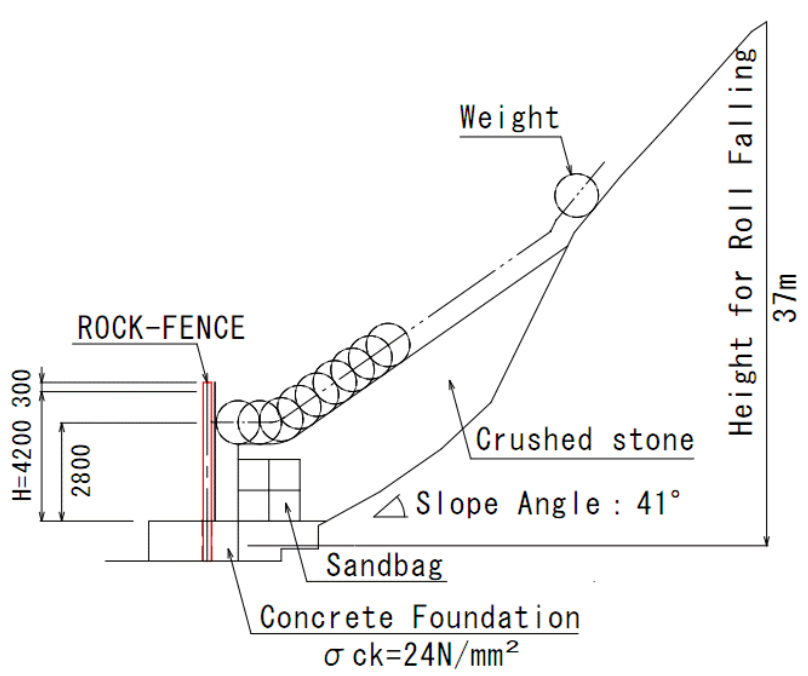

Fig. 4 Test diagram

The shape of the RC block was defined by the EOTA guidelines for falling-rock protection kits [4], as shown in Fig. 3. The RC block was covered with 6-mm-thick steel plates and it weighed 5.2 tons. The RC block was pushed from the peak of a slope at a height of approximately $37 \mathrm{~m}$. The RC block rolled down the slope and struck the fence, which was located at the bottom of the slope, as shown in Fig. 4. Arndt [5] used a rubber conveyor belt to prevent the block face from damage and to ensure that the RC block followed the desired path. However, because of its enormous size, the RC block used in the present study followed the expected path. 


\subsection{Pre-testing and Results for Energy Absorbers}

Two types of energy absorber were tested in the laboratory to examine the relationship between the friction force and slippage between the device and wire rope. Fig. 5 describes the configuration and procedures of the energy-absorber laboratory test. One end of the wire rope was held in an energy absorber, and the end of the U-bolt of the device was horizontally connected to the test frame far from the rest end of the wire rope at an interval of $5 \mathrm{~m}$. A 1340-kg weight was dropped along vertical guides. The tensile force of the wire rope was measured using a load cell attached to the rope end, and the displacement of the weight was measured using a rotary encoder through a belt connected to the weight. These data were recorded at $5 \mathrm{kHz}$.

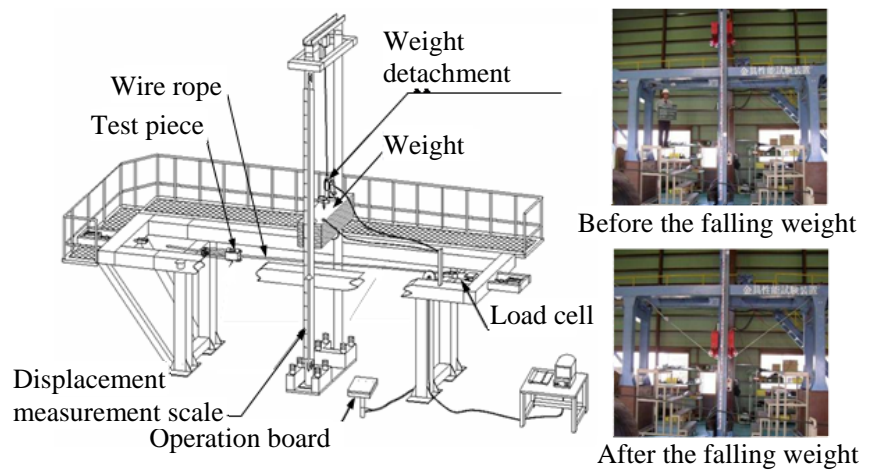

Fig. 5 Laboratory test for an energy absorber

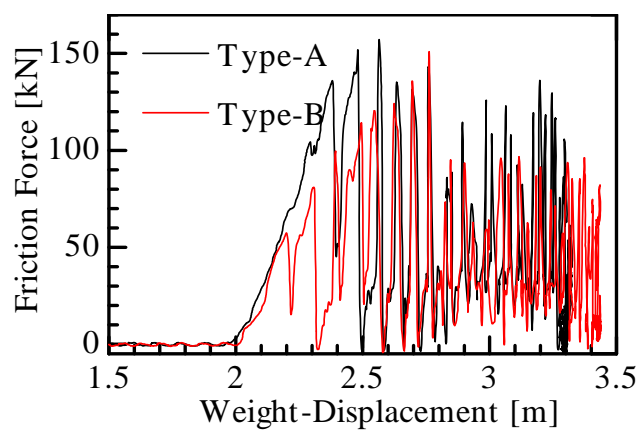

Fig. 6 Impulsive friction vs. weight displacement curve

Fig. 6 shows the results of impulsive friction-force laboratory tests on the two types of absorber. Independent of the device type, the impulsive friction force fluctuated widely. This fluctuation indicates that the wire rope exhibited alternating slipping and stopping behaviors. However, the fluctuation for the Type-B energy absorber began at a lower friction force than that of the Type-A energy absorber. This difference depends on the interval between the two steel blocks of the energy absorber, as mentioned in Section 2.1. No wire ropes broke during testing, although the maximum instantaneous friction forces for the Type-A and Type-B energy absorbers were 157 and $150 \mathrm{kN}$, respectively, and the nominal strength of the wire rope was $157 \mathrm{kN}$. Consequently, the average impulsive friction forces of the Type-A and Type-B energy absorbers were estimated to be 65.2 and $45.4 \mathrm{kN}$, respectively, by dividing the final potential energy of the weight by the total slippage between the device and the wire rope.

\section{RESULTS OF ROCK FENCE TESTS}

\subsection{Behavior of the Proposed Rock Fence}

Fig. 7 shows the collision points on each rock fence at mid-span. The collision point for Test No. 1 was slightly left of center, where the target was set at a height of $2.7 \mathrm{~m}$ from the concrete foundation.
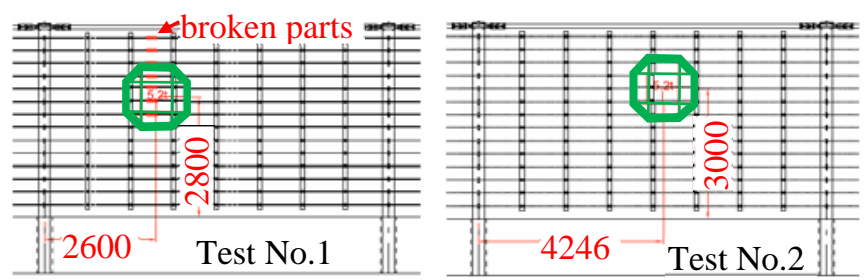

Fig. 7 Collision point on the rock fence at mid-span

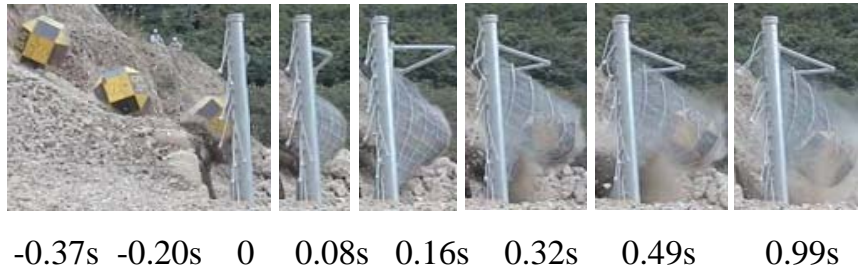

Fig. 8 Behavior of the rock fence (Test No. 1)
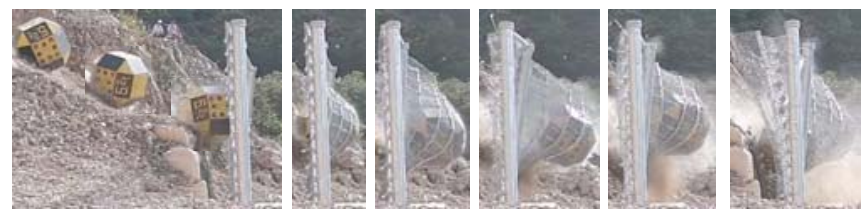

$-0.37 \mathrm{~s}-0.20 \mathrm{~s} \quad 0$

$0.08 \mathrm{~s} \quad 0.16 \mathrm{~s}$

0.32 s $0.49 \mathrm{~s}$

$0.99 \mathrm{~s}$

Fig. 9 Behavior of the rock fence (Test No. 2)

Figs. 8 and 9 show the impact process; i.e., the motion of the RC block and the behavior of the rock fence just before and during the collision in Test No. 1 and Test No. 2, respectively. These images indicate that the RC block was decelerated and captured by the fence in both tests. However, upon more detailed examination, differences between the two figures are recognized.

First, there is a considerable difference in the elongation of the wire meshes of the fences. The peak elongation of the wire mesh in Test No. 1 is clearly larger than that in Test No. 2. In Test No. 1, the RC block continued to move long after striking the fence, whereas, in Test No. 2, the RC block was stopped by the wire mesh $0.32 \mathrm{~s}$ after striking the fence and it then moved backward slightly. In Test No. 1, wire ropes No. 1 through No. 7 broke, as shown in Fig. 7, and it seems that there was no slippage between the wire ropes and absorbers.

\subsection{Impact Acceleration, Force, Velocity, and Energy}

Figs. 10 and 11 show the resultant acceleration vs. time for Test No. 1 and Test No. 2, respectively, before and after collision. As shown in these figures, the contact time can be estimated from the starting time of the high-speed camera and the frame number at which the RC block is observed striking the fence. Consequently, the acceleration and/or impact force due to the collision between the RC block and the fence can be determined from the diagram according to 
the contact time. The maximum acceleration and impact force were 280 to $340 \mathrm{~m} / \mathrm{s}^{2}$ and 1.46 to $1.77 \mathrm{MN}$, respectively. The acceleration (i.e., the impact force) in Test No. 1 is clearly larger than that in Test No. 2. This appears to be related to the fact that wire ropes No. 1 through No. 7 broke in Test No. 1 .

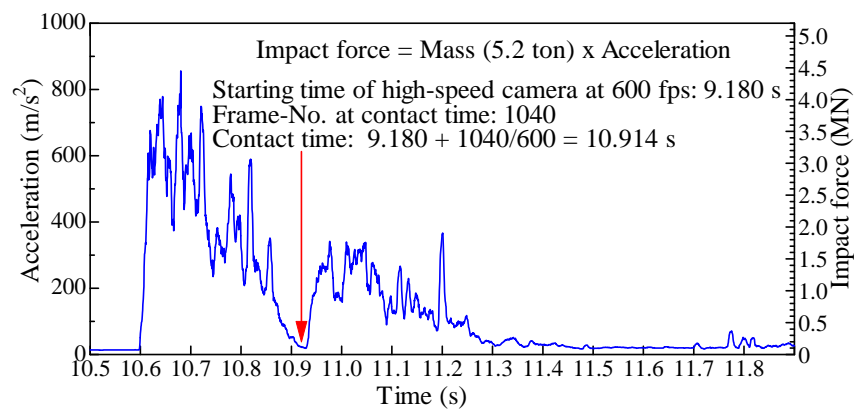

Fig. 10 Acceleration and impact force history (Test No. 1)

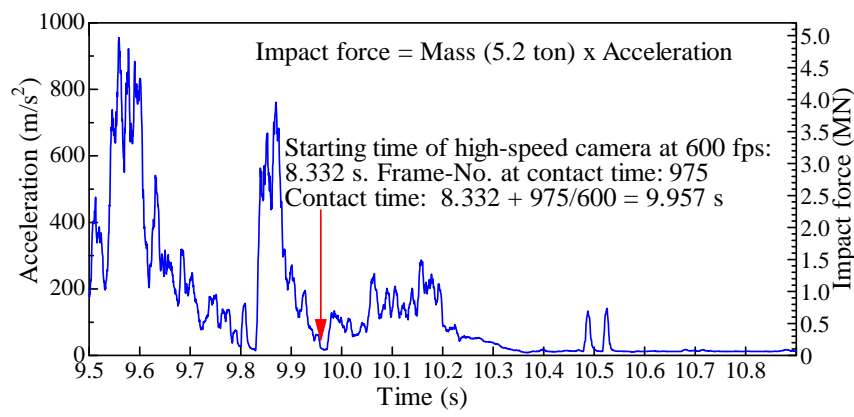

Fig. 11 Acceleration and impact force history (Test No. 2)

According to the Japan Road Association Hand Book of Rockfall [2], expected impact energy of approximately $1300 \mathrm{~kJ}$ was estimated for the site conditions of a slope of $41^{\circ}$, height of $37 \mathrm{~m}$, and surface friction coefficient of 0.25 . After the tests, however, the correct magnitude of the impact energy was calculated from measured impact velocities. The impact energy consists of translational energy $\left(E_{v}\right)$ and rotational energy $\left(E_{r}\right)$, which depend on the respective velocities of translation and rotation of the RC block just before collision:

$$
\begin{aligned}
& E_{v}=M V^{2} / 2, \quad E_{r}=I \omega^{2} / 2, \\
& E=E_{v}+E_{r},
\end{aligned}
$$

where $M, I, V$, and $\omega$ are the mass, moment of inertia, translational velocity, and rotational velocity of the RC block, respectively. These velocities of the RC block just before collision were evaluated by analyzing the motion recorded by the high-speed cameras.

Table 1: Velocity and impact energy

\begin{tabular}{cccccc}
\hline $\begin{array}{c}\text { Test } \\
\text { No. }\end{array}$ & $\begin{array}{c}\text { Translation } \\
\text { Velocity } V \\
(\mathrm{~m} / \mathrm{s})\end{array}$ & $\begin{array}{c}\omega \\
\text { Velocity }\end{array}$ & $\begin{array}{c}\text { Translation } \\
\text { Energy } \\
E_{v}(\mathrm{~kJ})\end{array}$ & $\begin{array}{c}\text { Rotation } \\
\text { Energy } \\
E_{r}(\mathrm{~kJ})\end{array}$ & $\begin{array}{c}\text { Total } \\
\text { Energy } \\
E(\mathrm{~kJ})\end{array}$ \\
\hline 1 & 16.0 & 14.3 & 666 & 140 & 806 \\
2 & 16.8 & 16.8 & 734 & 193 & 927 \\
\hline
\end{tabular}

Table 1 gives the magnitudes of the translational and rotational velocities and the corresponding impact energies. The total impact energy was lower than the expected energy.
The reason for this seems to be that the RC block passed through a gravel layer placed in front of the rock fence in order to control the trajectory of the RC block. Table 1 indicates that the rotational energy is $17 \%$ to $20 \%$ of the total impact energy. This value might be larger than the expected value [2] for actual rockfall, because the shape of the RC block used in this experiment rotates comparatively easily. Despite the larger rotational energy, the RC block did not pass over the fence because of the flexibility of the fence structure.

\section{NUMERICAL SIMULATION APPROACH}

\subsection{Finite Element Explicit Analysis}

Because the impact phenomena itself has a dynamic characteristic and large deformation, modeling the collision of an RC-block against a rock fence in numerical simulation based on a finite element method requires the consideration of both nonlinear geometrical and mechanical behaviors, and particularly the contact conditions. For this reason, rockfall impact was simulated in this study using a finite element method program for nonlinear dynamic analysis of an inelastic structure, namely LS-DYNA_971. This program has also been used to model the impact of falling rocks against galleries [6]. Using LS-DYNA, the main methodology is based on explicit time integration providing fast solutions for large deformation dynamics and complex contact problems [7]. It is thus possible to accurately model, with appropriate computational cost, a rockfall phenomenon lasting only a very short period of a few seconds and involving rapid variations in force, velocity, acceleration, and contact condition.

\subsection{Assumptions}

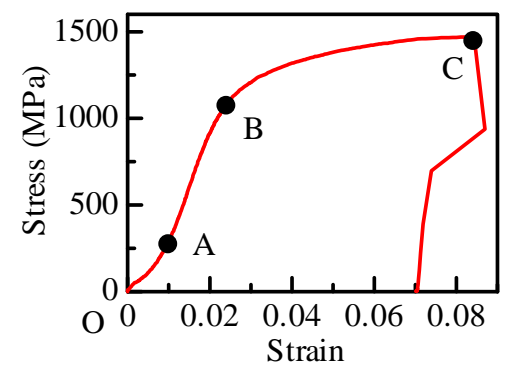

Fig. 12 Stress-strain curve derived from the steel-cable static tensile test

The collision with the wire-rope rock fence can only be numerically simulated by making simplifying assumptions based on engineering judgment.

First, the typical behavior of steel cable used as wire ropes in the wire-rope rock fence in a standard static tensile test is depicted in Fig. 12. Initially, the stress-strain curve shows nonlinear stiffening (from point $\mathrm{O}$ to point $\mathrm{A}$ ). Then (between points A and B) the curve is linear on the whole, but the stiffness begins to decrease significantly as the stress exceeds that at point $B$, and is associated with the considerable development of permanent strain until failure point (C) is reached.

Similarly, a typical static tensile test carried out on pieces of 
steel wire used as wire netting was conducted to assert their load-carrying capacity. The general structural behavior of steel wire in the static tensile test is similar to that of the abovementioned steel cable.

In both cases presented above, the authors are confronted with the problem of attaining a mechanical material model that should give accurate results in the dynamic range according to experimental results obtained in static tests only.

For simplicity, and to retain only the most important observed characteristics, the authors adopted constitutive laws that are uniaxial, rate independent, and elastic-plastic for both wire ropes and wire netting. This assumption might be disputed as being too rough an approximation. It should be pointed out, however, that according to experimental tests performed by Grillo et al. [8], the adoption of uniaxial elastic-plastic constitutive laws seems appropriate for steel members under impulsive loading.

Thus, the assumed constitutive laws for wire ropes and wire netting are shown in Fig. 13, which depicts the adopted stress-strain curve. The material property is modeled as being elastic-plastic, but the ultimate strength and the corresponding permanent strain are those deduced from static tensile tests.
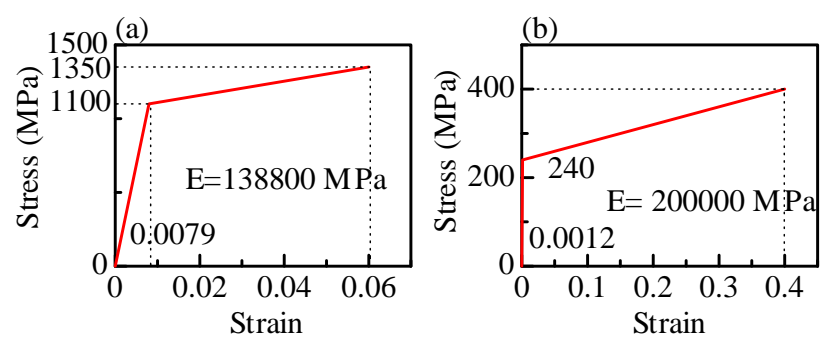

Fig. 13 Assumed stress-strain curve applied for wire ropes (a) and wire netting (b)

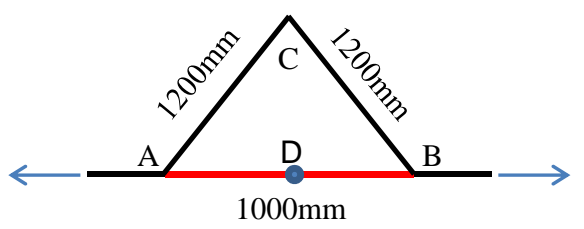

Fig. 14 Numerical model applied for energy absorber (a)

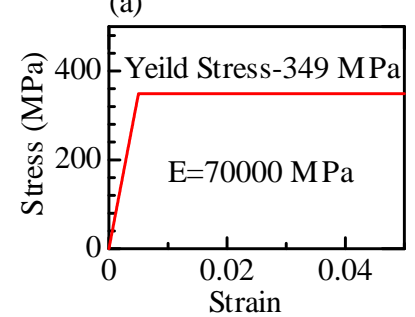

(b)

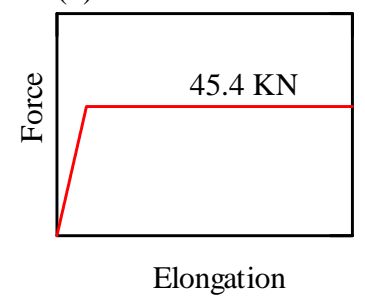

Fig. 15 Assumed stress-strain curve (a) and simplified behavior of absorbers (b)

Next the assumption for the energy absorber is introduced. Fig. 14 shows the configuration of the numerical model for energy absorbers with the expectation of the sliding phenomenon of the wire ropes through the absorbers and that the amount of absorbed impact energy is retained in the simulation analysis. In fact, in the case that the material property of the truss element AB follows the stress-strain curve sketched in Fig. 15a, the structural behavior of absorbers relies on the adopted elastic-perfectly plastic behavior as illustrated in Fig. 15b. If this is so, the problem of the amount of absorbed impact energy will be resolved. Moreover, the lengthening of element $\mathrm{AB}$ can be used to simulate the sliding phenomenon of the wire rope through the absorber, and when points $\mathrm{C}$ and $\mathrm{D}$ coincide with each other, the extension of element $\mathrm{AB}$ reaches a maximum of $1400 \mathrm{~mm}$, which is simply the extension length of wire ropes from the absorbers and entirely complies with the real structure.
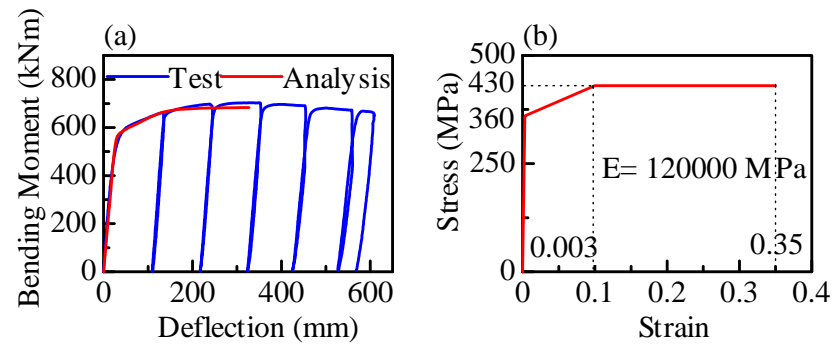

Fig. 16 Bending moment vs. deflection curve of posts (a) and assumed stress-strain curve of posts (b)

The next important assumption is applied to the posts constructed with concrete-filled steel tubes. LS-DYNA does not have an appropriate type of beam element or material properties to model this type of beam. Thus, a simplifying assumption was made primarily on the basis of using a steel tube beam element to model the post with assurance that the ultimate load-carrying capacity and ductility of the posts must be maintained. A three-point bending test on this post, which was supported by a span of $3.2 \mathrm{~m}$, was thus performed to determine the ultimate load-carrying capacity and ductility of the post, and the bending moment vs. deflection curve is sketched as a blue line in Fig. 16a. The steel tube beam whose outer diameter is equal to that of the post was then analyzed by searching for adequate values of thickness of the steel tube beam and Young modulus to attain the bending moment vs. deflection curve (as depicted by the red line in Fig. 16a) that best matches the blue line. The determined adequate values of the steel tube beam thickness and Young modulus were 30 $\mathrm{mm}$ and $120 \mathrm{GPa}$, respectively. Meanwhile, the corresponding original values were $12.7 \mathrm{~mm}$ and $206 \mathrm{GPa}$. From this result, the assumed stress-strain curve for the posts is sketched in Fig. 16b.

\section{TEST NO. 1 MODELING}

\subsection{Numerical Simulation}

The model that was the numerical simulation of the rock fence in Test No. 1 is referred to as Model No. 1 hereafter. Because there was no sliding between the wire ropes and energy absorbers in Test No. 1, Model No. 1 did not include the absorbers as components.

In Model No. 1, wire ropes are represented by beam elements and the Mat-Cable-Discrete type of material is applied without a failure strain definition in LS-DYNA. Thus, to consider the possibility of the failure of wire ropes, 
the truss element and Mat-Piecewise-Linear-Plasticity type of material with a failure strain condition were assigned to wire-rope elements in the impact area. The above approach was also applied for the wire netting. The wire ropes had a diameter of $18 \mathrm{~mm}$ and their effective cross-sectional area was determined to be $A_{\text {eff }}=134 \mathrm{~mm}^{2}$. In the case of the wire netting, the actual diameter was $5 \mathrm{~mm}$ and the effective cross-sectional area was $A_{\text {eff }}=19.63 \mathrm{~mm}^{2}$. The netting was made of intersecting wires forming a square grid of equal $50 \times 50 \mathrm{~mm}$ cells and the rock fence was coated with two alternate layers of wire netting. To reduce the number of elements with the aim of reducing analysis time, however, the wire netting in Model No. 1 was constructed as just one layer of a $150 \times 150$ square grid. Thus, the diameter of the wire netting was increased to $12.24 \mathrm{~mm}$ and the effective cross-sectional area was $A_{\text {eff }}=117.63 \mathrm{~mm}^{2}$, six times the original value.

Next, the posts, horizontal braces, and vertical braces were also modeled with the Mat-Piecewise-Linear-Plasticity type of material. Further detailed data pertaining to the type of element, constitutive law, and sectional properties are given in Table 2. The steel rings welded to the intermediate posts and vertical braces were represented by Mat-Rigid beam elements.

Table 2: Modeling data for post and braces

\begin{tabular}{cccc}
\hline $\begin{array}{c}\text { Structural } \\
\text { Component }\end{array}$ & $\begin{array}{c}\text { Type of } \\
\text { Element }\end{array}$ & $\begin{array}{c}\text { Constitutive } \\
\text { Law }\end{array}$ & $\begin{array}{c}\text { Sectional } \\
\text { Properties [mm] }\end{array}$ \\
\hline Post & Beam & Fig. 16b & $\varnothing 267.4 \times 30^{\mathrm{t}}$ \\
$\begin{array}{c}\text { Horizontal } \\
\text { Brace }\end{array}$ & Beam & Fig. 13b & $\varnothing 114.3 \times 4.5^{\mathrm{t}}$ \\
$\begin{array}{c}\text { Vertical } \\
\text { Brace }\end{array}$ & Shell & Fig. 13b & $9^{\mathrm{t}}$ \\
\hline
\end{tabular}

In the case of the real fence, the connection between wire ropes and wire netting is made with coils of steel wire having diameter of $5 \mathrm{~mm}$, with each coil consisting of five rings. With this kind of connection, there is no rigidity constraint between wire ropes and wire netting, with the expectation that they are almost independent of each other under an impact load. In Model No. 1, this connection is modeled by a type of beam element, namely a K-element. The magnitude of the Young modulus used for this element is very small (5 $\mathrm{MPa}$ ) in order to increase independent movement between the wire ropes and wire netting. The effective cross-sectional area of the K element is assumed to be $100 \mathrm{~mm}^{2}$, five times that of the wire netting.

Furthermore, consideration of the probable contact condition of components within the fence is critical to achieving a good result in modeling. Thus, the Auto-General contact condition was defined in Model No. 1.

The geometric picture of the wire-rope rock fence built in LS-DYNA, including the colliding block, is sketched in Fig 17. Initially, the fence lies flat in the vertical plane. The trajectory of the colliding RC block lies in a vertical plane perpendicular to the fence plane. The block is modeled according to its real shape and has an outer diameter D = $1408 \mathrm{~mm}$. According to EOTA guidelines [5], the volume of the block can be calculated as $V=17 / 24 \times D^{3}$. The
MAT-ELASTIC type of material is applied to the block with mass density of $2.63 \times 10^{-9}$ ton $/ \mathrm{mm}^{3}$, giving a weight of the block of 5.2 ton. In Model No. 1, the colliding block is placed immediately next to the fence plane and assigned initial conditions of angular velocity $\omega=14.3 \mathrm{rad} / \mathrm{s}$, translational velocity in the $\mathrm{Y}$ direction (normal to the fence plane) $\mathrm{v}_{\mathrm{y}}=15.757 \mathrm{~m} / \mathrm{s}$, and translational velocity in the $\mathrm{Z}$ direction $v_{z}=2.278 \mathrm{~m} / \mathrm{s}$; these values were obtained from the results for Test No. 1 .

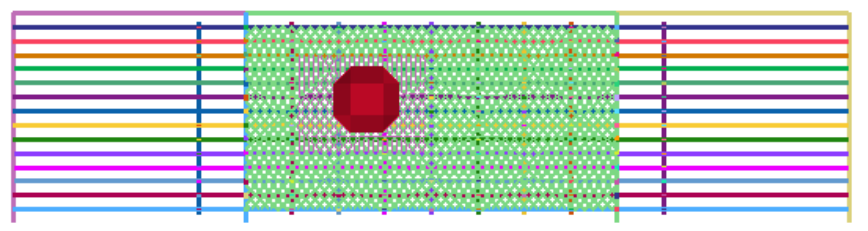

Fig. 17 Technical sketch of the wire-rope rock fence built in LS-DYNA

\subsection{Numerical Results and Comparison}

From animation results obtained for Model No. 1, overall results can be achieved. Despite there being no energy absorbers, the flexibility of the wire ropes, wire netting, and ductile posts was able to absorb the impact energy sufficiently to hold the RC block. The flexible behavior of the fence resulted in the final large deformation of the fence at the moment the RC block stopped. However, wire ropes No. 6 and No. 7 broke since the tension force exceeded their ultimate strengths. Likewise, there was also damage to the wire netting in the impact area, which if severe enough, would prevent the fence from catching the RC block. Fig. 18 shows the damage for wire ropes No. 6 and No. 7 and wire netting.

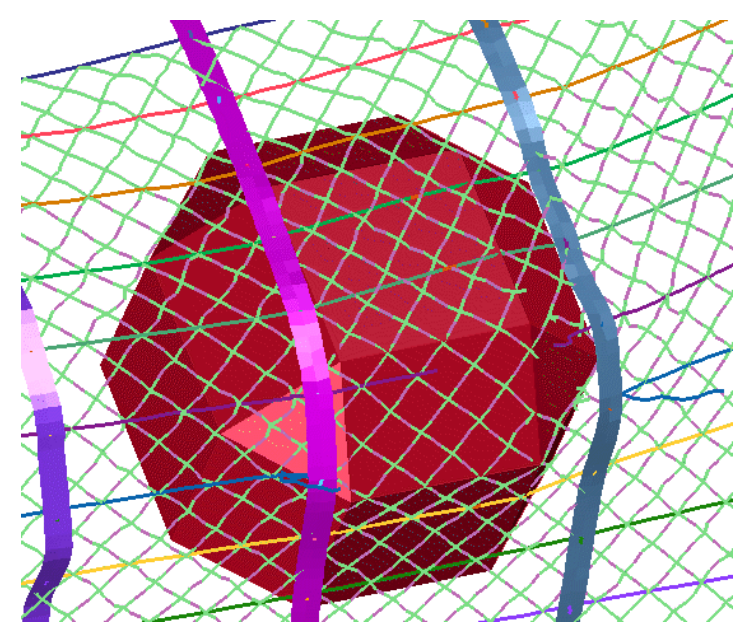

Fig. 18 The damage for wire ropes No. 6 and No. 7 and wire netting

The overall behavior of the wire-rope rock fence in numerical Model No. 1 and that in Test No. 1 are similar in terms of wire-rope breakage, deformation of the posts, horizontal braces, and vertical braces, and particularly the deformed form of the whole fence. However, there is a large difference in the number of broken wire ropes-seven in the crash test and two in numerical model.

Figs. 19 and 20 respectively show the variation in rope tension over time obtained from Model No. 1, measured in 
the impact area and the area next to an end post. It is obvious that the rope tension measured in the impact area is more severe than that measured in the region next to the end post for wire ropes No. 4 through No. 7, whose paths transit through the impact region. This contrasts with the case for wire ropes No. 1 through No. 3 (which do not directly pass through the impact region). In this case, the distribution of rope tension on wire ropes No. 1 through No. 3 is affected by how the impact momentum is transferred from the wire ropes (which are in direct contact with the block during the collision) to others via vertical braces and partly wire netting. This phenomenon arises from the direction of transfer of impact momentum not necessarily being perpendicular to the line of wire ropes.
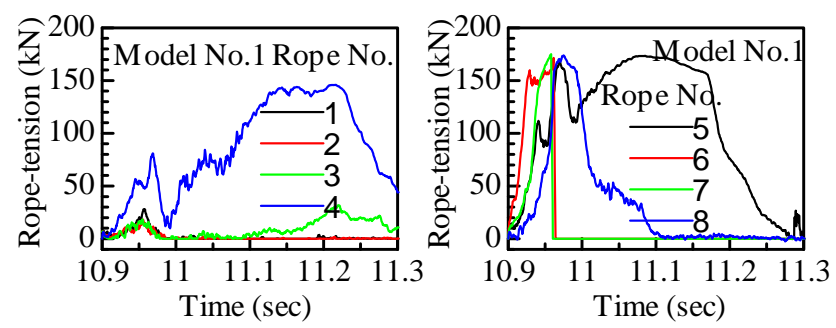

Fig. 19 Variation in rope tension over time (Model No. 1) measured in the impact area

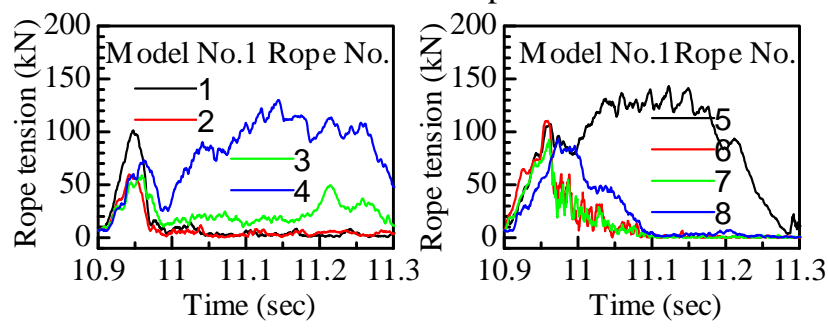

Fig. 20 Variation in rope tension over time (Model No. 1) measured next to an end post

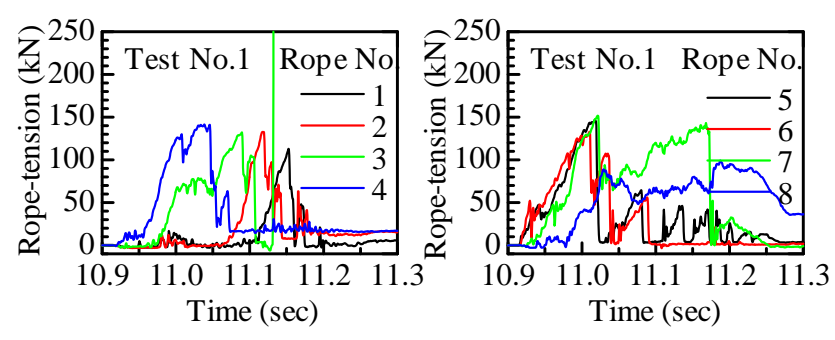

Fig. 21 Variation in rope tension over time (Test No. 1) measured next to an end post

As shown in Fig. 19, the tension forces of wire ropes No. 6 and No. 7 exceed $180 \mathrm{kN}$, the rope's ultimate strength, and rope breakage is thus a certainty. Furthermore, the rope tensions of wire ropes No. 5 and No. 8 are approximately the rope's critical strength, which means these wire ropes almost meet the failure criteria. These numerical results themselves denote good agreement with experimental results, except for wire ropes No. 1 and No. 2, which did not break.

Figs. 20 and 21 respectively show the rope-tension history attained from Model No. 1 and in Test No. 1 for the region next to the end post. The shapes of the two figures are similar, particularly in terms of the peak rope tension of wire ropes No. 4 to No. 8. It should be pointed out that although the peak values of the rope tensions of wire ropes No. 1 through No. 7 in Test No. 1 are well under the critical strength of $180 \mathrm{kN}$, all these ropes broke. From the rope-tension results in the impact region presented in Fig. 19 , it can be asserted that the peak value of the tensile force acting on wire ropes No. 1 to No. 7 in the impact region that could not be measured in Test No. 1 certainly reached the critical strength of the wire ropes.

\section{TEST NO. 2 MODELING}

\subsection{Numerical Simulation}

Model No. 2 was also built in LS-DYNA to simulate Test No. 2. Models No. 2 and No. 1 are similar on the whole, but the model of energy absorbing devices as shown in Fig. 14 has been added next to the end posts in Model No. 2 to approximately simulate the sliding behavior between wire ropes and absorbers in Test No. 2.

In this model, the RC block was assigned initial conditions of angular velocity $\omega=16.8 \mathrm{rad} / \mathrm{s}$, translational velocity in the $Y$ direction (normal to the fence plane) $\mathrm{v}_{\mathrm{y}}=16.645 \mathrm{~m} / \mathrm{s}$, and translational velocity in the $\mathrm{Z}$ direction $\mathrm{v}_{\mathrm{z}}=2.278 \mathrm{~m} / \mathrm{s}$, which were obtained from the results for Test No. 2 .

\subsection{Numerical Results and Comparison}

With the flexibility of the fence additionally reinforced by the energy absorbers, the amount of kinetic impact energy absorbed is considerably increased. This resulted in no breakage of the wire ropes, only little damage to the wire netting, and the RC block being caught. Without wire-rope breakage, the deflection of the fence in Model No. 2 is less than that in Model No. 1. These results agree with the results of Test No. 2. Fig. 22 shows the deformed state of Model No. 2. Thus, it can be asserted that the general numerical behavior of Model No. 2 agrees well with responses of the rock fence in Test No. 2.

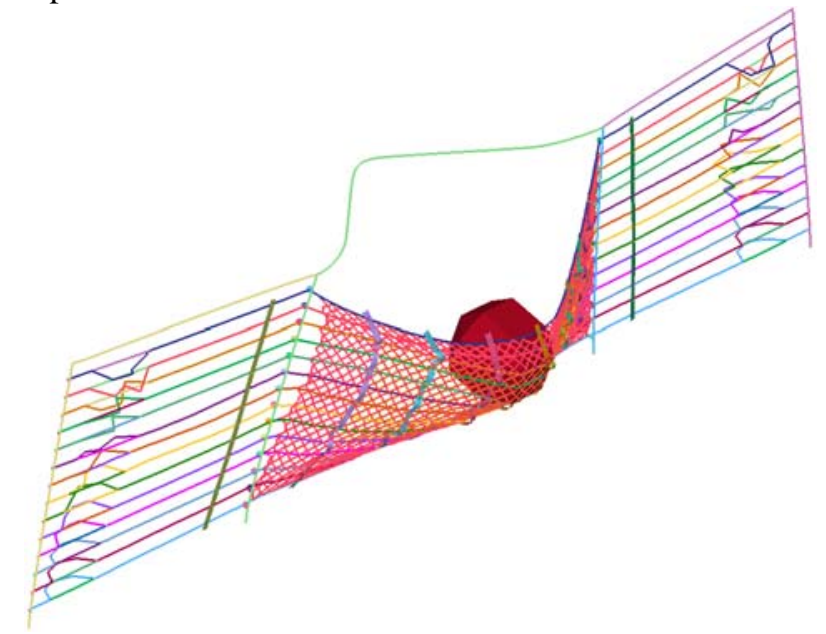

Fig. 22 Model No. 2 in the deformed state

Next, it is essential to compare rope-tension results for Model No. 2 and Test No. 2. First, there is a clear difference between the results for Model No. 2 in Figs. 23 and 24. Similar to the results obtained for Model No. 1 , the rope tension is not constant along the rope line but varies considerably. For Test No. 2, Fig. 25 illustrates the severe fluctuation of rope tension, and rope tension of wire ropes No. 2 through No.4 exceeded the rope's ultimate strength of 
$180 \mathrm{kN}$ but without breakage. This phenomenon is due to the mismatching of the cross-sectional size of U-bolts of absorbers resulting in unreliable measurement of rope tension over $135 \mathrm{kN}$, which exceeds the yield capacity of the U-bolt. Meanwhile the rope tension measured next to an end post does not vary in Model No. 2 as shown in Fig. 24. However, this could be acknowledged beforehand because the energy absorbers were simply modeled by truss elements with assumed material properties as mentioned previously. Here the important point that the rope tension results obtained for Model No. 2 indicate the behavior of the energy absorber model applied in Model No. 2 meet the authors' expectation as introduced in Section 5.2. The magnitude of rope tension remains constant at approximately $45 \mathrm{kN}$, equal to the average friction force in the Type-B energy absorber laboratory test, during the collision. In both experimental and numerical approaches, it is invaluable to assert that the function of energy absorber Type $B$ is effective. Permitting the wire ropes to slide through the Type B energy absorber not only dissipates the impact energy well but also prevents the wire ropes from breaking.
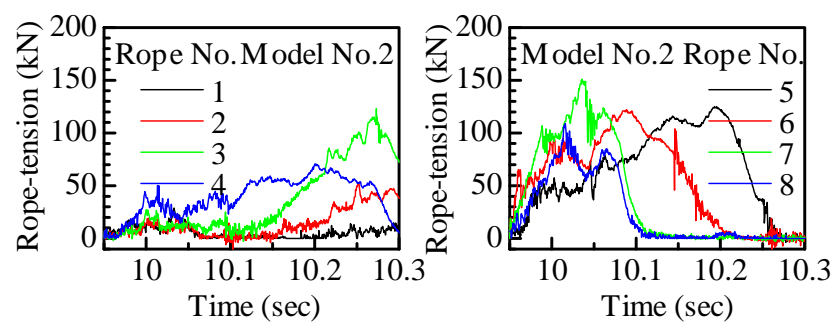

Fig. 23 Variation in rope tension over time (Model No. 2) measured in the impact area
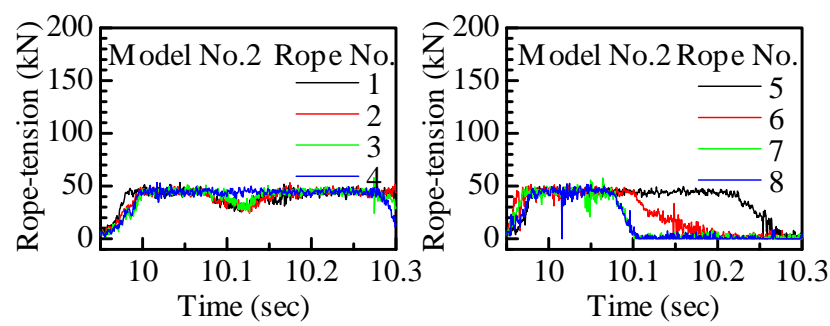

Fig. 24 Variation in rope tension over time (Model No. 2) measured next to an end post
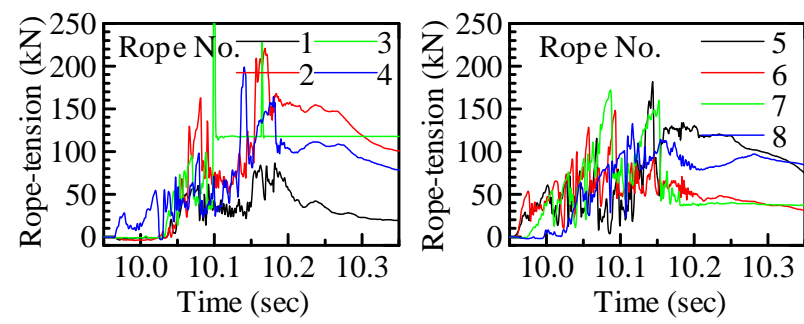

Fig. 25 Variation in rope tension over time (Test No. 2) measured next to an end post

\section{CONCLUSION}

This paper presented experimental results for a newly developed high-energy rock fence subjected to impact by an RC block rolling down a natural steep slope. The acceleration or impact force of the RC block rolling down a slope and colliding with the fence was measured with a measurement control system that was able to synchronize all measuring instruments. The impact energy was lower than that expected for the site conditions [2]. However, the rotational energy was $17 \%$ to $20 \%$ of the total impact energy, which is more than the value of $10 \%$ recommended by the Japan Road Association handbook [2]. Despite the higher rotational energy, the RC block did not bounce over the fence because of the flexibility of the fence structure.

Two types of energy absorber were examined in laboratory pre-tests and were applied to rock fences to confirm their energy-dissipation functions. The Type-B energy absorbing device was found to be effective in preventing wire-rope breakage and in dissipating the impact energy of rockfall. Additionally, numerical simulation using the finite element code LS-DYNA was performed to model the rockfall collision against the wire-rope rock fence in experimental tests No. 1 and No. 2. Generally, the numerical results agreed fairly well with those obtained from the crash tests, and they provide further understanding of the responses of each individual component and the fence as a whole. This work has been a fundamental first step in making parametric analyses and subsequently designing an adequate scheme for a rockfall protective fence.

\section{ACKNOWLEDGMENT}

The experiments were carried out in cooperation with High-Power Rock Fence Association. The authors wish to express greatly gratitude to all members of High-Power Rock Fence Association for their close collaboration.

\section{REFERENCES}

[1] Peila, D., Pelizza, S., \& Sassudelli, F. "Evaluation of Behaviour of Rockfall Restraining Nets by Full Scale Tests," Rock Mechanics and Rock Engineering, Vol.31(1), Springer-Verlag, 1998, pp.1-24.

[2] JRA (Japan Road Association), "Rockfall Mitigation Handbook (in Japanese),” Maruzen, 2000.

[3] Maegawa K. and Yoshida H., "Collision Tests on a New Type of Rock Barrier”, Proceeding of EASEC-5, 1995, pp.1927-1932.

[4] ETAG-027, "Guideline for European Technical Approval of Falling Rock Protection Kits,” European Organization for Technical Approvals (EOTA), 2008.

[5] B. Arndt, T. Ortiz, A. Keith Turner, "Colorado's Full-Scale Field Testing of Rockfall Attenuator Systems,” Transportation Research Board, 2009.

[6] Kishi, N., Ya Okada S., Hisashi Kon N., "Numerical Impact Response Analysis of Rockfall Protection Galleries,” Structural Engineering International, 2009, pp. 314-320.

[7] John O.Hallquist, "LS-DYNA Theory Manual," Livermore Software Technology Corporation, 2006

[8] Grillo F, Rega G, Vestroni F., "Ultimate resistance of structural steel elements for impulsive loads," Costruzioni Metalliche, Vol. 37(4), 1985, pp.185-201.

International Journal of GEOMATE, June, 2012, Vol. 2, No. 2 (Sl. No. 4), pp. 219-226

MS No.3e received January 25, 2012, and reviewed under GEOMATE publication policies.

Copyright (C) 2012, International Journal of GEOMATE. All rights reserved, including the making of copies unless permission is obtained from the copyright proprietors. Pertinent discussion including authors' closure, if any, will be published in the June 2013 if the discussion is received by Dec. 2012. Corresponding Author: Phuc Tran Van 